\title{
Métodos Estatísticos no Reconhecimento de Faces
}

\author{
Luciene de Oliveira Marin \\ Universidade Federal de Santa Catarina \\ Departamento de Automação e Sistemas \\ luciene@das.ufsc.br
}

\begin{abstract}
Resumo
Estuda-se o reconhecimento de faces usando métodos estatísticos clássicos do entudo de reconhecimento da padrões. Ilustrando a metodologia são apresentados exemplos concretos de sucesso e insucesso. Palavras-chave: Reconhecimento de padrões, Estatística, Visão robótica.
\end{abstract}

\begin{abstract}
It is presented the face recognition problem based on statistical methods. The methodology is illustrated by successful and failure examples.

Key-words: Patern recognition, Statistics, Robot vision.
\end{abstract}

\section{Introdução}

A face humana é uma imagem fascinante, uma inspiração infinita para artistas a milhares de anos. Além disso, a habilidade para reconhecer faces e entender as emoções que elas transmitem é uma das mais importantes habilidades humanas. Bebês podem identificar a face de suas mães dentro de meia hora de nascimento, a maioria de nós é hábil para instantaneamente reconhecer milhares de pessoas, haja visto que Napoleão poderia reconhecer todos os soldados regulares de seu exército [7]. O reconhecimento de faces é um exemplo importante do que se chama Reconhecimento de Padrão.

Os maiores reconhecedores de padrão na maioria dos exemplos são os seres vivos. Os animais reconhecem facilmente se um objeto é comida ou não. Cães identificam o cheiro ed seus donos e gatos detetam seu próprio cheiro nos lugares que marcou. As capacidades mentais dos animais, se divulgadas, espantariam muitos dos que trabalham em inteligência artificial usada em robótica. No entanto não é de hoje que se estuda e se verificam as enormes potencialidades mentais dos animais. Com efeito, já em 1911 Torndike [16] publicou um livro com estudos da psicologia animal.

Os humanos possuem uma capacidade enorme de identificação de formas (ex: letras), mas ainda não entendemos como os humanos reconhecem padrões.

\section{Formalizando o conceito de "ser parecido com"}

O conhecimento de mecanismos realizando o reconhecimento de padrão, permite construir máquinas que podem observar o ambiente, aprender e distinguir padrões de interesse do que está sendo visto, verificar e justificar decisões sobre as categorias dos padrões [20] e usando estatística [8]. Para isto, é necessário conceituar um conceito de ser parecido com" que se designa pela palavra Similaridade. Em linguagem matemática consiste em definir um espaço métrico [4], [9], (ver também [1], seção 7.8 e 7.9). Um espaço métrico é um par formado por um conjunto $U$ e uma função $d$ de valor real não negativo. Isto é, uma função $d$ que a todo par de elementos do conjunto, associa um real não negativo tal que:

$$
d: U \rightarrow \Re^{+}
$$

tal que:

$$
\begin{aligned}
\forall a, b \in U: & \\
d(a, b) & =0 \Leftrightarrow a=b \\
d(a, b) & =d(b, a) \\
f(a, c) & \leq f(a, b)+f(b, c)
\end{aligned}
$$

Definida uma função distância, é possível falar de faces similares e faces diferentes. Similares são aqueles que o valor da distância é pequeno, e diferentes aqueles em que a distância é grande. Convém no entanto estar consciente que a escolha da função $d$ encerra um grau de liberdade bastante grande, podendo ser difícil sua escolha. Um conjunto, no caso presente o conjunto de faces para o qual e definiu uma distância $d$ é dito um Espaço Métrico que é definido pelo par \{conjunto, distância\}.

Para efetuar o reconhecimento é necessário especificar um espaço métrico, em símbolos:

$$
<C, d>
$$

onde $C$ é o conjunto de casos considerado e $d$ a função distância do espaço métrico conhecido em RBC como função de similaridade. 
Duas funções distância, correntemente utilizadas, são a Distância Euclidiana e a Distância de Hamming. A distância euclidiana entre dois vetores (pods-se interpretar cada componente do vetor como o valor de um atributo da face):

$$
\begin{gathered}
\left|s_{1}, s_{2} \ldots s_{n}\right|^{T} \\
\left|u_{1}, u_{2} \ldots u_{n}\right|^{T}
\end{gathered}
$$

será então:

$$
d_{e}=\sqrt{\Sigma \alpha_{i}\left(s_{i}-u_{i}\right)^{2}}
$$

onde $\alpha_{i}$ são coeficientes de ponderação para poder levar em consideração a importância relativa da diferença de duas componentes dos vetores.

O nome distância euclidiana vem em homenagem ao geômetra Euclides que também, deu nome aos espaços métricos com distâncias euclidianas como espaço euclidiano. Trata-se do espaço onde vivemos e que temos por intuição ser o espaço real. Claro que um estudo mais aprofundado de física nos diria que o espaço euclidiano é apenas uma aproximação a tres dimensões do espaço onde vivemos em pontos bem perto do observador...o espaço do universo é bem diferente.

Outra distância bastante usada é a de Hamming ${ }^{1}$. Nesta, substitui-se a raiz quadrada da soma ponderada de quadrados, pela soma ponderada dos módulos das diferenças dos valores das várias componentes do vetor. Tem a vantagem de além de requisitar uma quantidade de cálculos numéricos menor do que no caso anterior, poder também tratar vetores cujas componentes tem valores inteiros e se os coeficientes de ponderação $\alpha$ forem também inteiros o valor da distância também o será. Assim temse:

$$
d_{h}=\Sigma_{1}^{n} \alpha_{i}\left(s_{i}-u_{i}\right)
$$

A distância de Hamming tem sido largamente empregada em vários campos até em verificação de transmissão de mensagens. Seu uso tem sido bastante generalizado e sua popularidade em aplicações em ciências da vida é grande. Por exemplo d'Uckem [6] usou esta distância em seu estudo de árvores cladísticas baseado na analogia com as linguagens formais sensíveis a contexto. Entretanto, neste trabalho, será usada a distância euclidiana, que é a mais usada (inexplicavelmente) em reconhecimento de padrões.

A abordagem estatística para reconhecimento de padrão merece especial atenção pois é a que mais tem sido estudada e usada na prática. No que se refere ao projeto de um sistema de reconhecimento, os seguintes assuntos requerem cuidadosa atenção: definição de classes de padrões, absorção do ambiente, representação de padrão, extração e seleção de características, análise de aglomerado ("cluster"), projeto e aprendizagem de classificador,

\footnotetext{
${ }^{1}$ A distância de Hamming é também conhecida como distância Manhatan, nome da ilha onde fica parte da cidade de New York, porque lá muitas ruas se cruzam perpendicularmente. Este termo, aceitável de um americano do norte, torna-se a evitar or outros indivíduos, sendo melhor homenagear seu inventor
}

seleção de exemplos de treinamento e teste, e avaliação de desempenho. Apesar de quase cinqüenta anos de pesquisa e desenvolvimento neste campo, problemas comuns de reconhecimento de padrões complexos com orientação, localização e escala arbitrários encontram-se sem solução. Novas e emergentes aplicações, tais como mineração de dados, pesquisa na web, restauração de dados multimídia, reconhecimento de face e reconhecimento de letras escrita à mão, requerem técnicas robustas e eficientes de reconhecimento de padrão [8].

$\mathrm{O}$ objetivo deste trabalho consiste em pesquisar a respeito do emprego de técnicas estatísticas de processamento de imagens no reconhecimento de padrões relacionados a faces humanas. O mesmo apresenta também uma breve exposição a respeito da abordagem estatística para sistemas de detecção de face, pois ela também é essencial para se desenvolver algoritmos eficientes e robustos em sistemas completamente automáticos, capazes analisar informações de faces humanas [21].

Um estudo do reconhecimento de faces usando redes neurais foi apresentado previamente pela autora em [3]. Este estudo foi feito no contexto do Projeto Sorface. Para maiores detalhes ver [1], [11], [23], [24], [25], [22].

\section{Reconhecimento de Padrão}

Reconhecimento automático, descrição, classificação, e agrupamento de padrões são problemas importantes em diversas disciplinas de engenharia e científicas tais como biologia, psicologia, medicina, marketing, visão computacional, inteligência artificial, e percepção de distância. Este problema preocupa os pesquisadores há muitos anos. Referência clássica é são os livros de Tou [17] e Pavel [14] ambos enfatizando técnicas estatísticas.

Mas o que é um padrão? Define-se um padrão “como o oposto do caos; uma entidade, vagamente definida, a qual pode ser dada um nome ". Por exemplo, um padrão poderia ser uma imagem de impressão digital, uma palavra escrita a mão, uma face humana, ou um sinal de voz. Dado um padrão, reconhecê-lo ou classificá-lo pode consistir de uma das seguintes tarefas:

- classificação supervisionada (p.e. análise discriminante) na qual o padrão de entrada é identificado como um membro de uma classe pré-definida, ou seja, a classe é definida pelo projetista do sistema,

- classificação não supervisionada (p.e. agrupamento) no qual o padrão é determinado por uma "fronteira"de classe desconhecida, ou seja, as classes são aprendidas baseadas na similaridade dos padrões.

As quatro abordagens mais conhecidas para reconhecimento de padrão são:

1. casamento de modelo,

2. classificação estatística,

3. casamento sintático ou estrutural, e 


\section{4. redes neurais.}

Estes modelos não são necessariamente independentes e às vezes o mesmo método de reconhecimento de padrão existe com diferentes interpretações [8].

\section{Reconhecimento de Padrão Esta- tístico}

O reconhecimento de padrão estatístico tem sido usado com sucesso para projetar uma quantidade de sistemas comerciais de reconhecimento. Na abordagem estatística, cada padrão é representado em termos de características, medidas ou atributos e é visto como um ponto em um espaço $d$-dimensional. O objetivo é escolher determinadas características que permitam a vetores padrão, pertencentes a diferentes categorias, ocupar regiões compactas e disjuntas em um espaço de características $d$-dimensional. A efetividade do espaço de representação (conjunto de características) é determinado por quão bem separados podem ser os padrões de diferentes classes. Dado um conjunto de padrões de treinamento de cada classe, o objetivo é estabelecer decisões de fronteiras no espaço de características, aos quais os padrões separados pertenceriam a diferentes classes. $\mathrm{Na}$ abordagem teórica de decisão estatística, a decisão de fronteiras é determinada por distribuições de probabilidade de padrões pertencentes a cada classe, a qual deve ser específica ou aprendida. Um sistema de reconhecimento é operado em dois modos: treinamento (aprendizagem) e classificação (teste) veja na Fig. 1.

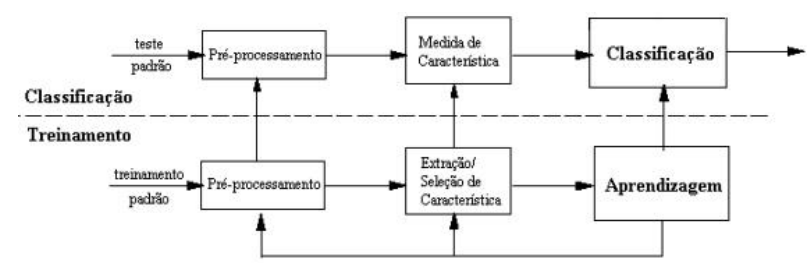

Figura 1: Modelo para Reconhecimento de Padrão Estatístico

A função do módulo de pré-processamento é retirar o padrão de interesse de uma paisagem, remover ruídos, normalizar o padrão, e qualquer outra operação a qual contribui na definição de uma representação compacta do padrão. No modo treinamento, o módulo de extração/seleção de características procura características apropriadas para a representação de padrões de entrada e o classificador é treinado para particionar o espaço de características. O caminho de volta permite a um projetista otimizar o pré-processamento e estratégias de extração/seleção de características. No modo classificação, o classificador treinado determina o padrão de entrada para uma das classes de padrões sob considerações baseadas na medidas das características.

O processo de tomada de decisão no reconhecimento de padrão estatístico pode ser sumarizada como segue. Um dado padrão está determinado a uma das c categorias $w_{1}, w_{2}, \ldots, w_{c}$ baseado em um vetor de $\mathrm{d}$ valores de característica $x=\left(x_{1}, x_{2}, \ldots, x_{d}\right)$. As características tem uma densidade de probabilidade ou função massa (dependendo se as características são contínuas ou discretas) condicionada à classe de padrão. Assim um vetor padrão $x$ pertencente a uma classe $w_{i}$ é visto com uma observação extração ao acaso de uma função de probabilidade classe-condicional $p(x \mid w i)$. Um número bem conhecido de regras de decisão, incluindo regra de decisão Bayes, a regra da probabilidade máxima (a qual pode ser vista como um caso particular de regra Bayes), e a regra Neyman-Peason são eficazes para definir a decisão de fronteira. A regra de decisão de Bayes “ótima"para a minimização do risco (exceto valores da função de perda) pode ser declarado como segue:

$$
R\left(w_{i} \mid x\right)=\sum_{j=1}^{c} L\left(w_{i}, w_{j}\right) \cdot P\left(w_{j} \mid x\right)
$$

Ela determina o padrão de entrada $x$ para a classe $w_{i}$ para o qual o risco condicional é mínimo, onde $L\left(w_{i}, w_{j}\right)$ é a perda da função implicada sobre $w_{i}$ determinada quando a classe verdadeira é $w_{j}$ e $P\left(w_{j} \mid x\right)$ é a probabilidade posterior. No caso de função perda $0 / 1$, como definido na Eq. 2, o risco condicional torna-se a probabilidade condicional de classificação errônea.

$$
L\left(w_{i}, w j\right)= \begin{cases}0, & \mathrm{i}=\mathrm{j} \\ 1, & \mathrm{i} \neq \mathrm{j}\end{cases}
$$

Para esta escolha da função perda, a regra de decisão Bayes pode ser simplificada como segue: Ela determina o padrão de entrada $x$ para a classe $w_{i}$ se

$$
P\left(w_{i} \mid x\right)>P\left(w_{j} \mid x\right), \text { para todo } j \neq i
$$

Várias estratégias são utilizadas para projetar um classificador para um reconhecimento de padrão estatístico, dependendo da espécie de informação disponível sobre densidades de classe-condicional. Se todas as densidades de classe-condicional são completamente especificadas, então a regra de decisão Bayes ótima pode ser usada para projetar o classificador. Entretanto, densidades de classe-condicional são freqüentemente não conhecidas na prática e devem ser aprendidas dos padrões de treinamento disponíveis. Se a forma da densidade classecondicional é conhecida (p. e. Gaussian multivariado), mas alguns dos parâmetros de densidades (p. e. vetores médio e matrizes de covariância) são desconhecidos, então nós temos um problema de decisão parametrizada. Uma estratégia comum para estes tipos de problemas é substituir os parâmetros desconhecidos na função densidade por seus valores estimados, resultando no então chamado classificador Bayes "plug-in". A estratégia Bayesiana ótima nesta situação requer informação adicional na forma de uma distribuição prévia nos parâmetros desconhecidos. Se a forma da densidade classe-condicional é não conhecida, então nós operamos em um modo não parametrizado. Neste caso, nós devemos ou estimar a função de densidade (p. e., abordagem Janela Parzen) ou 
diretamente construir a decisão de fronteira baseada no treinamento dos dados (p. e., regra do k mais próximo vizinho). De fato, um perceptron multicamada pode ser visto como um método supervisionado não paramétrico o qual constrói uma decisão de fronteira. Outra dicotomia em reconhecimento de padrão estatístico é a do aprendizado supervisionado (chamado treinamento de exemplos) versus o aprendizado não supervisionado (não chamado de treinamento de exemplos). O chamado treinamento de exemplos representa a categoria ao qual o padrão pertence. Em um problema de aprendizado não supervisionado, algumas vezes o número de classes deve ser aprendido diante as estruturas de cada classe. As várias dicotomias que aparecem em reconhecimento de padrões estatísticos são mostradas na árvore de estruturas da Fig. 2.

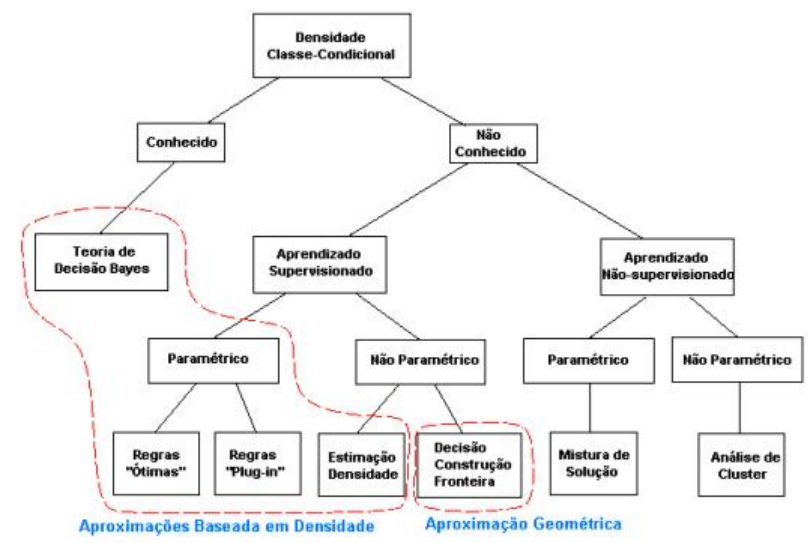

Figura 2: Várias Abordagens no Reconhecimento de Padrão Estatístico

Como se percorre a árvore de cima para baixo e da esquerda para a direita, menos informações estão disponíveis para o projetista de sistema e como um resultado, a dificuldade de classificação dos problemas aumenta. Em alguns casos, a maioria das abordagens em reconhecimento de padrões estatístico (nós folhas da árvore da Fig. 2) são tentativas de implementar a regra de decisão Bayes. O campo de análise de cluster essencialmente trata com problemas de tomada de decisão no modo não paramétrico e aprendizado não supervisionado. Além disto, na análise de cluster o número de categorias ou clusters talvez nem mesmo sejam especificadas; a tarefa é descobrir uma categorização razoável dos dados (se alguma existir). Algoritmos de análise de cluster junto com várias técnicas para visualização e projeção de dados multi-dimensionais são também referidas como métodos de análise de dados exploratórios.

Ainda outras dicotomias em reconhecimento de padrão estatístico podem ser baseadas se as decisões de fronteiras são obtidas diretamente (abordagem geométrica) ou indiretamente (abordagem baseada em densidade probabilística) como mostrado na Fig. 2. A abordagem probabilística requer estimar a primeira função de densidade, e então construir as funções discriminantes as quais especificam as fronteiras de decisão. Por outro lado, a abordagem geométrica freqüentemente constrói fronteiras de decisão diretamente através de funções de custo fixo. Não é importante qual regra de classificação ou decisão é usada, ela deve ser treinada usando os exemplos de treinamento disponíveis. Como um resultado, o desempenho de um classificador depende de ambos o número de exemplos de treinamentos disponíveis bem como valores específicos de exemplos. Ao mesmo tempo, o objetivo de um projetista de sistema de reconhecimento é classificar exemplos de testes futuros os quais são provavelmente diferentes dos exemplos de treinamento. Então, otimizando um classificador para maximizar sua performance no conjunto de treinamento pode não sempre resultar na performance desejada em um conjunto de teste. A habilidade de generalização de um classificador referese para sua performance em classificar padrões testes os quais não foram usados durante o estágio de treinamento. Uma pobre habilidade de generalização de um classificador pode ser atribuída por qualquer um dos seguintes fatores:

- o número de características é muito grande relativo ao número de exemplos de treinamento,

- o número de parâmetros desconhecidos associados com o classificador é grande (p. e., classificadores polinomial ou uma rede neural larga), e

- um classificador é intensivamente otimizado no conjunto de treinamento (treinamento demasiado - "overtraining"); isto é análogo ao fenômeno de "overfitting"em regressão quando existe muitos parâmetros livres.

"Overtraining" tem sido investigado teoricamente por classificadores que minimizam a taxa de erro aparente (o erro no conjunto de treinamento). Estudos clássicos sobre capacidade e complexidade de classificadores ( $p$. e. aqueles tendo muitos parâmetros independentes) podem ter uma larga capacidade, isto é eles são hábeis para representar muitas dicotomias para um conjunto de dados dado. Uma medida freqüentemente usada para a capacidade é o dimensionamento Vapnik-Chervonenkis (VC). Estes resultados podem também ser usados para mostrar algumas propriedades interessantes, por exemplo, a consistência do classificador fixo. O uso prático dos resultados sobre classificadores complexos foram inicialmente limitados porque os limites propostos no número requerido de exemplos de (treinamento) foram muito conservativos. No recente desenvolvimento de máquinas de vetor de suporte, entretanto, os resultados tem mostrado ser de total utilidade. A armadilha sobre adaptação de estimadores para o conjunto de treinamento dado é observado em muitos estágios de um sistema de reconhecimento de padrão, tais como redução de dimensionalidade, estimação de densidade, e projeto de classificador. Uma solução certa é sempre usar um conjunto de dados (conjunto teste) independente para avaliação. Na ordem de evitar a necessidade de ter muitos conjuntos testes independentes, estimadores são freqüentemente baseados em subconjuntos de dados rotulados, preservando diferentes partes dos dados para otimização e avaliação [8]. 


\section{Abordagens Estatísticas para o Reconhecimento de Face}

O reconhecimento de face a partir de imagens fotográficas e imagens de vídeo está emergindo como uma atividade na área de pesquisa com numerosas aplicações comerciais e coação de lei. Estas aplicações requerem algoritmos robustos para reconhecimento de faces humanas sobre diferentes condições de iluminação, expressões faciais e orientações. Um esquema geral usado para reconhecimento de face é ilustrado na Fig. 3 [13].

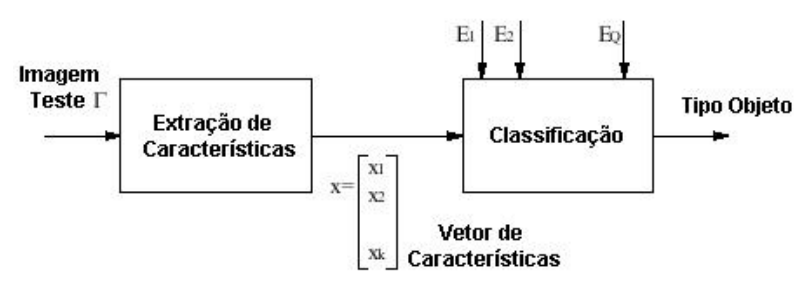

Figura 3: Esquema Geral de Reconhecimento de Face

$\mathrm{O}$ vetor de características $x=\left[x_{1}, x_{2}, \ldots, x_{k}\right]$ extraído de uma imagem teste ( é comparado a cada um dos vetores de características extraídos de todos os exemplos de imagens de face $E_{1}, E_{2}, \ldots, E_{Q}$ e uma medida de similaridade no espaço de características é usado para classificar a imagem entrada como uma das imagens de exemplos. A razão de imagens de face classificadas corretamente sobre o número total de faces classificadas pelo sistema de reconhecimento, define o desempenho de reconhecimento (taxa de reconhecimento) do sistema. Baseado na extração de características e técnicas de classificação usadas, as abordagens de reconhecimento de face segundo [13] são:

- Parametrização geométrica

- Estatística

- Redes neurais

Dentre as abordagens estatísticas para reconhecimento de face, as mais usadas são:

- Métodos de correlação

- Métodos de decomposição de valor singular

- Métodos baseados em expansão Karhune-Loeve

- Métodos baseados em discriminante linear Fisher

- Métodos baseados em modelo de Markov escondido

\subsection{Métodos de Correlação}

A maioria direta dos procedimentos usados para reconhecimento de face é o casamento entre as imagens teste e um conjunto de treinamento de imagens baseado na medida de correlação. O casamento técnico, neste caso é baseado na computação do coeficiente de correlaçãocruzada $\mathrm{CN}$, definido por:

$$
C_{N}=\frac{E I_{T} T-E I_{T} E T}{\sigma\left(I_{T}\right) \sigma(T)}
$$

Onde $I_{T}$ é a imagem a qual deve ser combinada com a template $T, I_{T} T$ representa o produto pixel-por-pixel, $E$ é o operador médio e $\sigma$ é o desvio padrão sobre a área sendo combinada. Esta normalização reorganiza a template e a distribuição de energia da imagem de forma que suas médias e variâncias combinem. Entretanto, métodos baseados em correlação são muito dependentes de iluminação, rotação e escala. Os melhores resultados para a redução das variações de iluminação foram obtidos usando intensidade de gradiente $\left(\left|\delta_{x} I_{T}\right|+\left|\delta_{y} I_{T}\right|\right)$. Porque o método de correlação é computacionalmente muito caro, a dependência do reconhecimento sobre a resolução da imagem tem sido investigada. Estudos mostram que o reconhecimento baseado na correlação tem um bom nível de desempenho usando templates pequenas de $36 \times 36$ pixeis [13].

\subsection{Métodos Baseados em Expansão Karhunen-Loëve}

\subsubsection{Reconhecimento Usando "Autofaces"}

O método "Autofaces"tem sido implementado com o propósito de comparações, pois ele foi um dos melhores sucedidos dentre os algoritmos avaliados. Este método foi desenvolvido no M.I.T. por Turk and Pentland [18], [15]. No qual é chamado Análise de Componente Principal onde poucos parâmetros são usados para representação, extraídos da face. Estes parâmetros são obtidos pela projeção da face sobre um sistema de coordenadas dados por "autovetores"da matriz de covariância do conjunto de treinamento. Estes autovetores, imagens deles mesmos, são chamados "autofaces"e transpõe um vetor de espaço chamado espaço face. Cada face é então codificada por meios de suas coordenadas no espaço face. O comparação ("matching") de duas faces, para saber se são semelhantes, corresponde a um cálculo da distância entre suas representações do espaço de faces [15].

O trabalho de [10] apresenta uma nova abordagem para classificação de padrão chamada combinação linear mais próxima (NLC) (de "Nearer Linear Combination") para reconhecimento de face baseado em autoface. Ele supõe que múltiplos vetores prototípicos são disponíveis através de classes, cada vetor começando de um ponto em um espaço autoface. Uma combinação linear de vetores prototípicos pertencentes a uma face classe é usada para definir uma medida de distância de um vetor "a reconhecer"para a classe, a medida é definida como sendo a distância Euclidiana da "face a reconhecer"para a combinação linear mais próxima (portanto NLC). Isto contrasta a classificação do vizinho mais próximo (NN) onde um vetor a reconhecer é comparado com cada vetor prototípico individualmente. Usando uma combinação linear de vetores prototípicos, ao invés de cada um deles individualmente, estende-se a capacidade de representação dos protótipos pela generalização, através de interpolação e extrapolação. Experimentos mostraram que isto conduz 
a melhores resultados do que os métodos de classificação existentes. A Fig. 4 ilustra o uso da técnica NLC para deduzir a posição de $y$ (ângulo de visão, iluminação, ou expressão) relativa a dois protótipos $x_{k}(k=1,2)$. Com este estudo ele mostra que a abordagem NLC reduz significativamente a taxa de erro do padrão e da abordagem de classificação NN em autoface baseada no reconhecimento de face. Este aprimoramento é devido a representação NLC que expande a capacidade representacional de protótipos de faces na base de dados: Variações na iluminação, ângulo de visão e na expressão entre imagens de faces prototípicas são consideradas por variações em seus pesos que determinam a combinação linear.
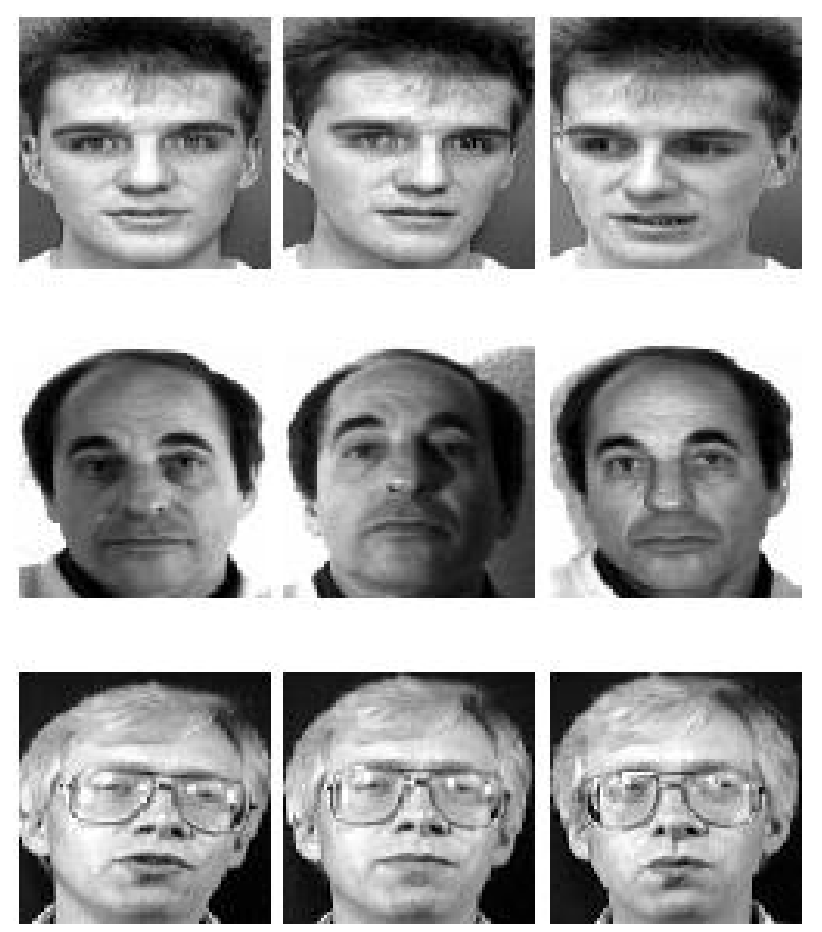

Figura 4: (Linha Topo) Faces sob mudanças no ângulo de visão. A face a reconhecer $y$ (esquerda) está a um ângulo relativo central das duas faces prototípicas $x_{1}$ e $x_{2}$, vistas a um ângulo direito e esquerdo respectivamente. (Linha do Meio) Faces sob mudanças de iluminação. A face a reconhecer $y$ (esquerda) é iluminada por uma luz à direita e é comparada a duas faces prototípicas $x_{1}$ e $x_{2}$, uma iluminada pela esquerda e outra pelo centro, respectivamente. (Linha Inferior) Faces sob mudanças de expressões.

\subsubsection{Reconhecimento sob Condições de Visualiza- ção Gerais}

\section{A Abordagem Paramétrica}

Esta abordagem extende a capacidade do método autoface para reconhecimento de objetos em imagem 3D sob diferentes condições de iluminação e visualização. Dadas $N$ imagens de objetos tidas sob $P$ condições de visão e $L$ condições de iluminação, um conjunto de imagem universal é construído o qual contém todos os dados disponíveis. Desta maneira um simples "espaço paramétrico"descreve a identificação do objeto, bem como as condições de visualização ou iluminação. A decomposição autoface deste espaço é usada para extração e classificação de características. Entretanto, na ordem de garantir discriminação entre diferentes classes de objeto o número de autovetores usados neste método é incrementado, comparado ao método Autoface clássico [13].

\section{A Abordagem "View-Based"}

Baseada na decomposição autoface, [Pentland et al] apud [13] desenvolveu uma abordagem baseada em autoespaço "view-based"para reconhecimento de faces humanas sob condições gerais de visão. Dados $N$ indivíduos sob $P$ diferentes visões, o reconhecimento é executado sob condições gerais de visão. A abordagem "viewbased"é essencialmente uma extensão da técnica autoface para múltiplos conjuntos de autovetores, um para cada orientação de face. Para distribuir as múltiplas visões, num primeiro estágio desta abordagem, a orientação da face teste é determinada e o autoespaço o qual melhor descreve a imagem de entrada é selecionado. Isto é efetuado calculando o erro descrição residual (distância do espaço de características: DFFS) para visão espaço. Uma vez a visão apropriada sendo determinada, a imagem é projetada sobre esta visão espaço e então reconhecida. A abordagem "view-based"é computacionalmente mais intensiva do que a abordagem paramétrica porque $P$ diferentes conjuntos de $V$ projeções são requeridas ( $V$ é o número de autofaces selecionadas para representar cada autoespaço). Entretanto, isto não implica que um fator de tempo $P$ na computação é necessariamente requerida. Calculando progressivamente os coeficientes autovetores enquanto corta espaços de visão alternativos, o custo do uso de $P$ autoespaços pode ser grandemente reduzido. Naturalmente, a representação "view-based" pode render mais precisão de representação do que o fundamento geométrico.

No trabalho de [12], foi apresentada uma abordagem para automaticamente determinar a orientação da cabeça para construir um conjunto "view-based" de $M$ autoespaọs separados, cada variação foi capturada de $N$ indivíduos em uma visão comum. O autoespaço viewbased é essencialmente uma extensão da técnica autoface para múltiplos conjuntos de autovetores, um para cada combinação de escala e orientação. Alguém poderia pensar desta arquitetura como um conjunto paralelo de "observadores", cada um tentando explicar os dados da imagem com seu conjunto de autovetores. Neste view-based, abordagem múltiplos-observadores, o primeiro passo é determinar a localização e orientação do objeto objetivo pela seleção do autoespaço que melhor descreve a imagem de entrada. Isto é efetuado pelo o cálculo do erro descrição residual (a métrica "distância-do-espaçode-face") usando cada um dos autovetores dos espaọs de visão. Uma vez determinado o espaço de visão apropriado, a imagem é descrita usando os autovetores de tal espaço de visão, e então reconhece-o. Tem-se avaliado esta abordagem usando dados similares como mostrado na Fig. 5.

Estes dados consistem de 189 imagens em nove vi- 


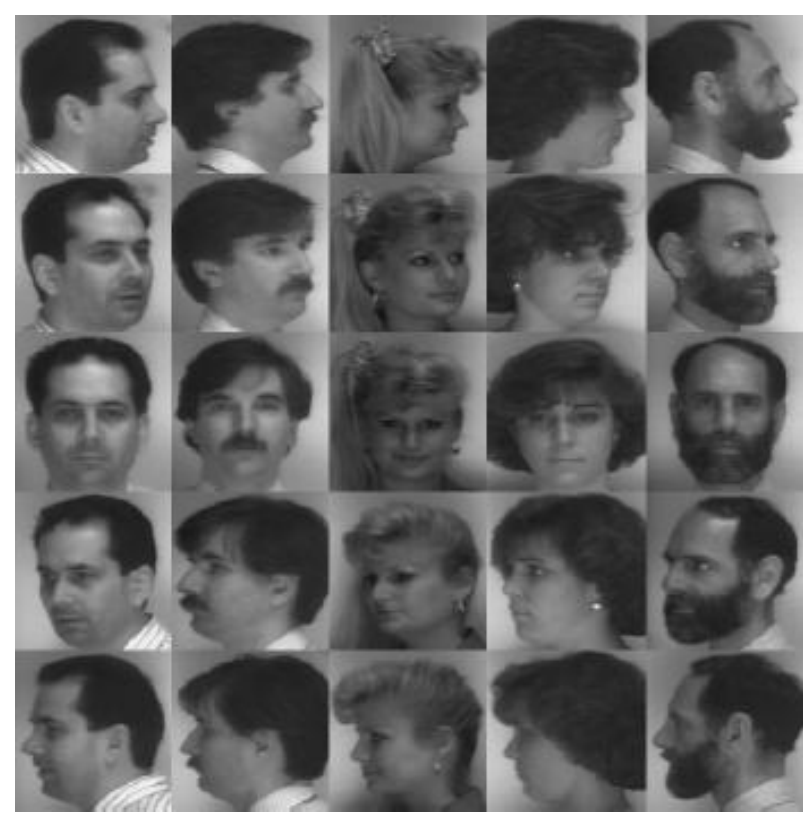

Figura 5: Algumas das imagens usadas para testar a precisão do reconhecimento de face a despeito de amplas variações na orientação da cabeça. A precisão média de reconhecimento foi $92 \%$, e a orientação do erro teve um desvio padrão de $15^{\circ}$.

sões de 21 pessoas. As nove visões de cada pessoa foram igualmente espaçadas de $-90^{\circ} \mathrm{a}+90^{\circ}$ diante de um plano horizontal. Os dados foram fornecidos por Westinghouse Eletronic Systems. O desempenho de interpolação foi testado pelo treinamento sobre um subconjunto de visões disponíveis $\pm 90^{\circ}, \pm 45^{\circ}, 0^{\circ}$ e testando em visões intermediárias de $\pm 68^{\circ}, \pm 23^{\circ}$. A média da taxa de reconhecimento obtido foi de $92 \%$.

\subsubsection{Reconhecimento Características" \\ Usando "Auto-}

Consiste do uso de características faciais para reconhecimento de face. Isto pode ser visto como uma representação modular ou por camadas da face, onde uma descrição grosseira (resolução baixa) de toda a cabeça é aumentada por detalhes adicionais (resolução alta) para salientar características da face. A técnica autoface foi estendida para detectar características faciais. Para cada característica da face, um espaço de características é construído pela seleção da maioria de auto-Características significantes (autovetores correspondentes para grandes autovalores da matriz de correlação de características). Na representação autocaracterística a equivalente "distância do espaço de característica"(DFFS) pode ser efetivamente usado para detecção de características faciais. A detecção de fatores DFFS foi estendida para detecção de características sob diferentes visões geométricas pelo uso ou de view-based autoespaço ou um autoespaço paramétrico [13].

Em [12] a técnica autoface é facilmente estendida para a descrição e codificação de características faciais, dando "eigeneyes", "eigennoses", "eigenmouths". Estu- dos do movimento do olhos indica que estas características faciais particulares representam importante limite para fixação, especialmente em uma tarefa de discriminação. Então é esperado uma melhora no desempenho de reconhecimento pela incorporação de uma camada adicional de descrição em termos de características faciais. Isto pode ser visto como se uma representação modular ou em camadas de uma face, onde uma grosseira (baixaresolução) descrição de toda a cabeça é aumentada por detalhes adicionais (alta-resolução) em termos de salientar características faciais. Com a habilidade para de forma confiante detectar características faciais através de uma larga escala de faces, pode-se automaticamente gerar uma representação modular de uma face. A utilidade desta representação em camada (autoface mais autoCaracterísticas) foi testada em um pequeno subconjunto de sua base de dados de face.

Selecionou-se uma amostra representativa de 45 indivíduos com duas vistas por pessoa, correspondendo a diferentes expressões faciais (neutro vs. sorridente). Este conjunto de imagem foi particionado entre um conjunto de treinamento (neutro) e um conjunto de teste (sorridente). Visto que a diferença nas expressões faciais é primeiramente articulada na boca, esta característica particular foi discartada para o propósito de reconhecimento. A Fig. 6 mostra as taxas de reconhecimento como uma função do número de autovetores para autoface-somente, autocaracterística-somente e a representação combinada. O que é surpreendente é que (para este pequeno conjunto de dados no mínimo) a autocaracterística sozinha foi suficiente para adquirir uma (assintótica) taxa de reconhecimento de $95 \%$ (igual para aqueles da autofaces).

Mais surpreendente, às vezes, é a observação que em menores dimensões de autoespaço, autocaracterística apresentam desempenho de melhor qualidade no reconhecimento autoface. Finalmente, pelo uso da representação combinada, ganha-se um leve melhoramento na taxa de reconhecimento assintótica (98\%). A potencial vantagem da camada autocaracterística é a habilidade de superar as desvantagens de um método autoface padrão. Um puro reconhecimento autoface pode ser enganado por grosseiras variações na imagem de entrada (chapéus, barbas, etc.). Na Fig. 7(a) mostra visões testes adicionais de 3 indivíduos por cima de um conjunto de dados de 45 indivíduos. Estas imagens teste são indicativas do tipo de variação o qual pode conduzir a combinações falsas: uma mão próxima a face, uma pintura de face, e uma barba. A Fig. 7(b) mostra as combinações mais próximas encontradas baseada na classificação de padrão autoface. Nenhuma das 3 combinações correspondem ao indivíduo correto. Por outro lado, a Fig. 7(c) mostra a mais próxima combinação baseada nos olhos e nariz, e resulta na correta identificação em cada caso. Este simples exemplo ilustra a vantagem de uma representação modular na desambigüidade de combinações autofaces falsas. 


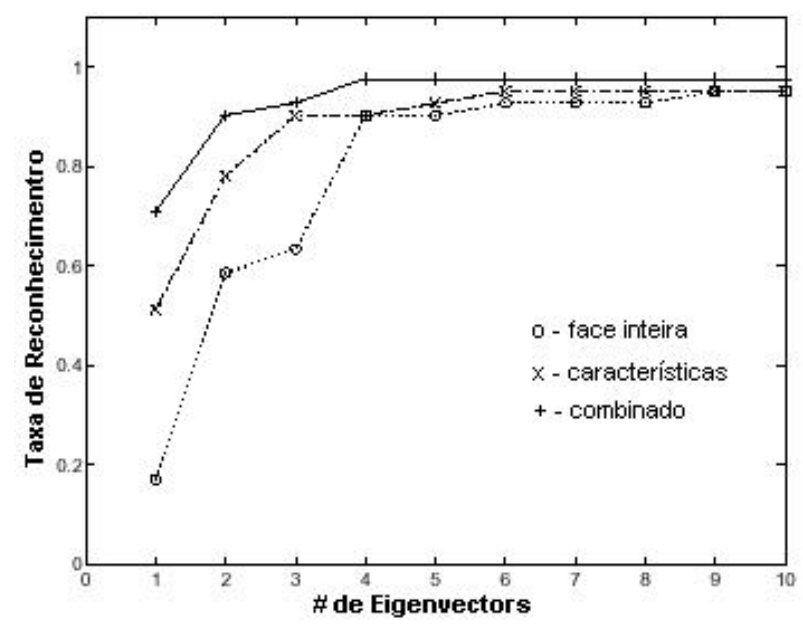

Figura 6: Taxas de reconhecimento para autofaces, autocaracterística e a representação modular combinada

\subsection{Método Discriminante Linear "Fisherfaces"}

Neste novo método há a redução da dimensionalidade do espaço de características usando Discriminante Linear de Fisher (FLD) (do inglês "Fisher Linear Discriminant") [2] and [13]. O FLD usa o classe de informação de um grupo e desenvolve um conjunto de vetores de características nos quais variações de diferentes faces são enfatizadas enquanto diferentes exemplos de faces combinadas com condições de iluminação, expressões faciais e orientação são desenfatizadas.

\subsection{Método Baseado no Modelo Markov Escondido}

O Modelo Markov Escondido (HMM) (do inglês "Hide Markov Model")é um conjunto de modelos estatísticos usados para caracterizar propriedades estatísticas de um sinal. HMM são feitos de dois processos interrelacionados: (1)uma secreta não observável cadeia de Markov com número finito de estados, um estado de transição, matriz de probabilidade e um estado inicial, distribuição de probabilidade. (2)um conjunto de funções de densidade probabilidade associado a cada estado. Os elementos de uma HMM são:

- $N$, o número de estados no modelo. Se $S$ é o conjunto de estados, então $S=S_{1}, S_{2}, \ldots, S_{N}$. O estado do modelo no tempo $t$ é dado por $q_{t} \in S$, $1 \leq t \leq T$, onde $T$ é o tamanho da seqüência de observação (número de frames).

- $M$, o número de diferentes símbolos de observação. Se $V$ é o conjunto de todas as observações de símbolos possíveis (também chamado de modelo codebook), então $V=v_{1}, v_{2}, \ldots, v_{M}$.

- A, o estado de transição matriz de probabilidade, i.e. $A=a_{i j}$ onde:

$$
a_{i j}=P\left[q_{t}=S_{j} \mid q_{t-1}=S_{i}\right],
$$

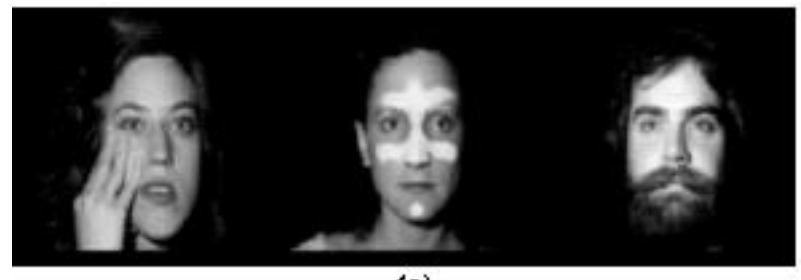

(a)

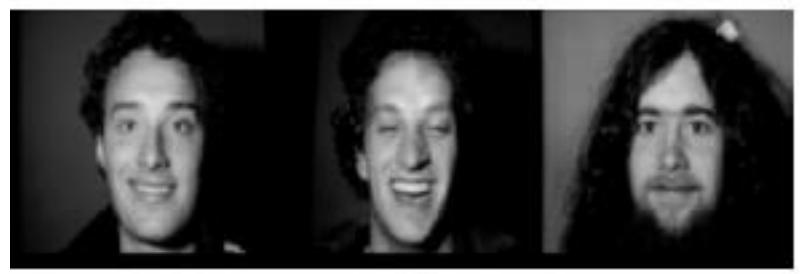

(b)

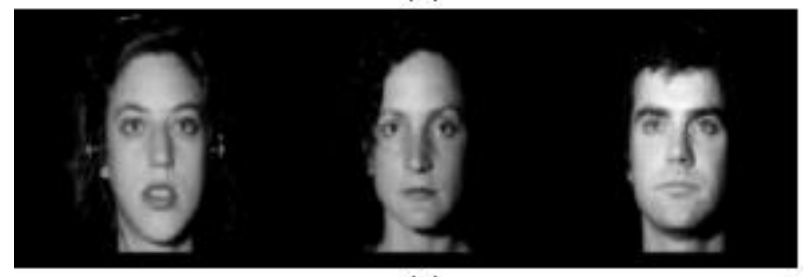

(c)

Figura 7: (a) Visões testes, (b) Autoface combinadas, (c) Autocaracterísticas combinadas.

para:

$$
\begin{gathered}
1 \leq i, j \leq N, 0 \leq a_{i, j} \leq 1 \\
\sum_{j=1}^{N} a_{i j}=1
\end{gathered}
$$

para:

$$
1 \leq i \leq N
$$

- B, o símbolo de observação da matriz de probabilidade, i.e. $B=b_{j}(k)$, onde,

$$
b_{j}(k)=p\left[O_{t}=v_{k} \mid q_{t}=S_{j}\right]
$$

para:

$$
1 \leq j \leq N, 1 \leq k \leq M
$$

e $O_{t}$ é o símbolo de observação no tempo t.

- $\pi$, distribuição de estado inicial, i.e. $\pi=\pi_{i}$ onde:

$$
\pi_{i}=P\left[q_{1}=S_{i}\right], 1 \leq i \leq N
$$

Usando uma notação estenográfica, uma HMM é definida como:

$$
\lambda=(A, B, \pi)
$$

A caracterização acima corresponde a uma discreta HMM, onde as observações são caracterizadas como símbolos discretos escolhidos de um alfabeto finito $V=$ $v_{1}, v_{2}, \ldots, v_{M}$. Em uma HMM de densidade contínua, os estados são caracterizados por observações contínuas de 
funções densidades. A maioria geral das representações dos modelos de funções de densidade de probabilidade (pdf) é uma mistura finita da forma:

$$
b_{i}(O)=\sum_{k=1}^{M} c_{i k} N\left(O, \mu_{i k}, U_{i k}\right), 1 \leq i \leq N
$$

onde $c_{i k}$ é uma mistura de coeficiente para a késima mistura de estados $i$. Sem perda de generalidade $N\left(O, \mu_{i k}, U_{i k}\right)$ é assumida ser uma pdf Gaussian com o vetor médio $\mu_{i k}$ e a matriz de covariância $U_{i k}$.

HMM tem sido usado largamente para reconhecimento de voz, onde os dados são naturalmente unidimensionais (1D) ao longo do eixo do tempo. Entretanto, o equivalente completamente conectado em duas dimensões HMM dominaria uma grande quantidade de problemas computacionais. Tentativas tem sido feitas para usar representações multi-modelos que conduzem ao um pseudo 2D HMM. Estes modelos são atualmente usados no reconhecimento de caracteres. Foi proposto em [Samaria et al] apud [13] o uso de 1D contínuo HMM para reconhecimento de face. Assumindo que cada face está em uma posição ereta e frontal, características ocorrerão em uma ordem previsível, isto é, testa, olhos, nariz etc. Esta ordenação sugere o uso de um modelo "topbottom", onde somente transições entre estados adjacentes do modo de cima para baixo são permitidos. Os estados do modelo correspondem a características faciais como testa, olhos, nariz, boca e queixo. A sequência de observação $O$ é gerada de uma imagem $\mathrm{X}$ x Y usando uma janela amostra X x L com X x M pixels sobrepostos (Fig. 8) [13].
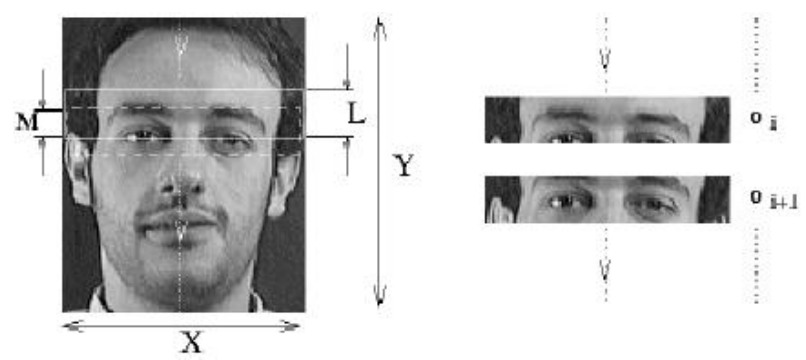

Figura 8: Técnica de imagem amostra para reconhecimento HMM

Cada vetor de observação é um bloco de $L$ linhas. Há uma linha M sobreposta entre sucessivas observações. A sobreposição permite que as características sejam capturadas de uma maneira a qual é independente da posição vertical, enquanto um particionamento disjunto da imagem poderia resultar em características truncadas ocorrendo através das fronteiras dos blocos.

Desempenho do Reconhecimento: Neste trabalho, o desempenho do reconhecimento foi testado em uma pequena base de dados de 50 imagens que das quais não faziam parte da base de dados de treinamento 24 imagens [37] apud [13]. As imagens do conjunto de teste contém faces com diferentes expressões faciais, detalhes faciais (com ou sem óculos) e variações na iluminação.
Nesta base de dados os autores relataram uma taxa de reconhecimento de $84 \%$. No mesmo banco de dados a taxa de reconhecimento foi obtida pela execução do método autoface foi de $73 \%$. Entretanto, a computação envolvida para o reconhecimento levou aproximadamente 12 segundos para classificar uma imagem usando o conjunto de 24 modelos de treinamento, em uma estação de trabalho SunSparc II.

\subsection{Misturas de Subespaços Linear Local}

No trabalho de [5] temos a análise de desempenho de reconhecimento de um modelo de misturas de subespaços linear local que pode ser combinado para treinamento dos dados usando algoritmo de maximização de expectativa. O modelo misturado tem melhor desempenho do que um classificador "vizinho mais próximo"operando em um subespaco PCA (análise de componente principal) ou expansão Karhunen-Loëve. Foi mostrado o quanto esta abordagem de reconhecimento é robusta para modelagens de faces como na Fig. 9 Em uma abordagem para visualizar a modelagem da face, imagens de face $\mathrm{N}$ pixel normalizadas são projetadas sobre um subconjunto de $\mathrm{D}$ autovetores ou autofaces de matriz de covariância estimada do conjunto de treinamento de imagens. O subespaço D-dimensional atravessado por estas autofaces ortogonais é o subespaço no qual os dados de treinamento tem a maior variação. De fato, estas autofaces são iguais aos primeiros $\mathrm{D}$ principais componentes obtidos da análise de componente principal. A distância de uma nova imagem de entrada deste subespaço linear tem sido usada totalmente com sucesso para detectar faces.

Foi considerado que uma mistura de $\mathrm{K}$ subespaços linear como uma mistura de $\mathrm{K}$ analisadores de fator, onde cada analisador de fator tem o mesmo número $\mathrm{D}$ de fatores. Seja $\Lambda_{k}$ o fator carregado de matriz para o analisador $k$. Cada analisador também terá sua própria imagem média $\mu_{k}$ e sua própria diagonal de matriz de covariância de ruído de pixel $\Psi_{k}$. O modelo misturado pode ser escrito:

$$
\begin{aligned}
p(x, z, k) & =P(k) p(z \mid k) p(x \mid k, k) \\
& =\pi_{k} N(z ; O, I) N\left(x ; \mu_{k}+\Lambda_{k} z, \Psi_{k}\right)
\end{aligned}
$$

onde $\pi_{k}$ é a proporção de mistura do componente $k$. Em seguida, integrando sobre $z$, temos

$$
\begin{gathered}
p(x \mid k)= \\
\frac{\exp \left[-\frac{1}{2}\left(x-\mu_{k}\right)^{\prime}\left(\Lambda_{k} \Lambda_{k}^{\prime}+\Psi_{k}\right)^{-1}\left(x-\mu_{k}\right)\right]}{(2 \pi)^{N / 2}\left|\Lambda_{k} \Lambda_{k}^{\prime}+\Psi_{k}\right|^{1 / 2}}
\end{gathered}
$$

Após isto ser computado deve-se obter então:

$$
p(x \mid k)=\sum_{k} \pi_{k} p(x \mid k)
$$

Se dado um modelo de mistura para cada classe de dados (por exemplo, indivíduo para ser reconhecido), isto procederá dando $p\left(x \mid C_{i}\right)$ para diferentes classes $C_{1}, C_{2}, \ldots$. Aplica-se então a regra de Bayes para fazer a decisão do reconhecimento. 
No processo de compilação de uma base de dados de seqûëncias de vídeo de um número relativamente pequeno de indivíduos (100), mas com alta variação nas expressões faciais e poses, tais como na Fig. 9 que mostra algumas das imagens de vídeo mais testadas da base de dados. Esta aplicação mostrou-se altamente robusta para o reconhecimento de face em ambientes fechados como uma área de escritório.
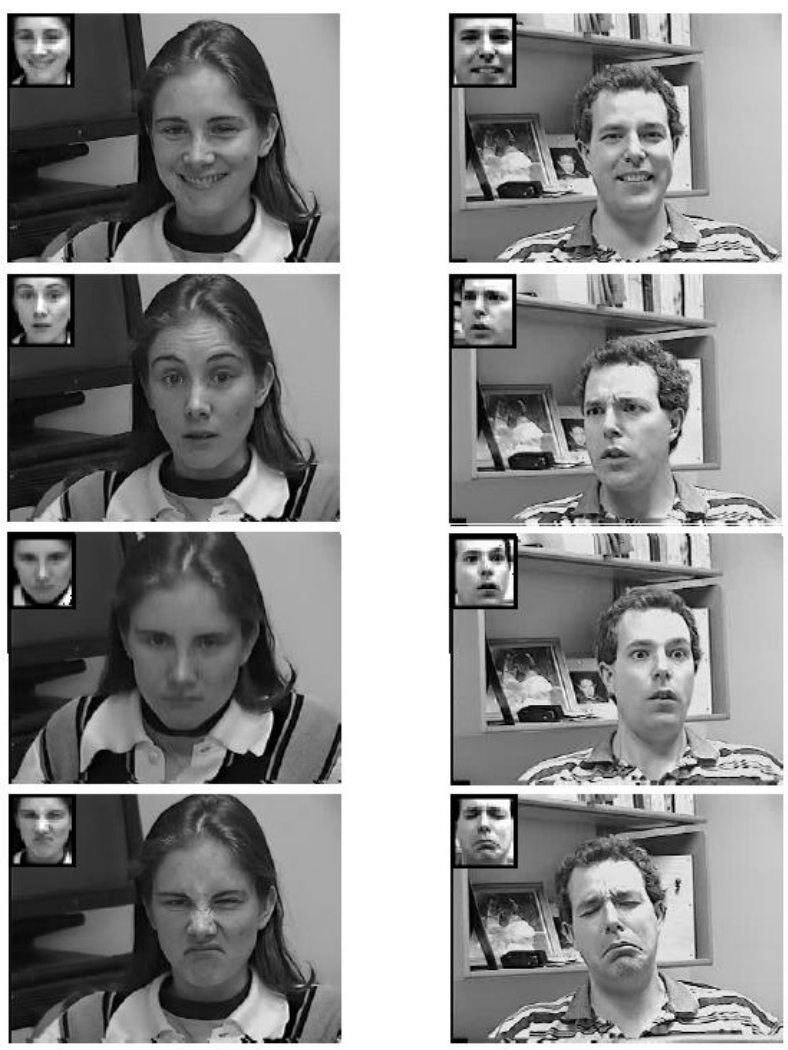

Figura 9: Exemplos de formas de vídeo e faces normalizadas

\section{Detecção Estatística de Faces}

O trabalho de [21] mostra que a interação humano computador tem se tornado uma ativa área de pesquisa em que interfaces mais amigáveis e efetivas vem sendo desenvolvidas. Entre todas as interface humano computador, é mais comum acreditar que faces humanas é um dos mais efetivos meios, visto que ela carrega enormes informações as quais computadores podem reagir de acordo. Por exemplos, computadores podem ajustar seu comportamento pelo conhecimento das emoções do usuário, através de suas expressões faciais. Atenção visual é outro exemplo onde computadores podem reagir baseados nos interesses de seus usuários. Em direção a este objetivo, reconhecimento de face e expressão facial tem atraído muita atenção recentemente e embora já venha sido estudada a mais de vinte anos por psicólogos, neuro-cientistas e engenheiros. Muitas aplicações interessantes e úteis tem sido desenvolvidas com estes esforços. A maioria dos métodos existentes assumem que faces humanas de- vem ser extraídas de imagem estática ou de uma seqüência de imagens e focalizar algoritmos de reconhecimento. Entretanto, detecção de face de uma imagem simples ou uma seqüência de imagens é uma tarefa muito desafiante e não mais fácil do que reconhecimento de face. Detecção de face é consideravelmente difícil porque envolve localização de face com nenhum conhecimento prévio de sobre suas escalas, localizações, orientações(ereta, rotacionada) com ou sem oclusões, com diferentes posições (frontal, perfil). Expressões faciais e condições de iluminação também alteram por completo aparências de faces, tornando-se difícil detectá-las. Além disto, a aparência de faces humanas em uma imagem depende da posição de humanos e de visões dos dispositivos de aquisição. Os desafios associados com problemas de detecção de face podem ser atribuídos aos seguintes fatores:

- Posições: Faces podem aparecer em diferentes posições (frontal, ângulo de 45 graus, perfil, parte superior inclinada para baixo) o que faz suas aparências variar nas imagens. Algumas posições podem ocluir características faciais tal como olhos e nariz.

- Presença ou ausência de características estruturais comuns: Faces humanas fazem diferentes características faciais tais como barba, bigode ou óculos. Além disso, tais características tem diferenças drásticas na aparência por causa da localização e tamanho.

- Expressões faciais: A aparência de faces humanas são afetadas por suas expressões faciais.

- Oclusões: Faces podem ser ocluídas por outros objetos. Em uma imagem com um grupo de pessoas, algumas faces podem parcialmente ocluir outras faces.

- Condições de formulação da imagem: fatores de imagem afetam o resultado da aparência de faces humanas quando a imagem é formulada, através de problemas causados tais como escala, orientação, visão, e condições de iluminação.

É claro que estes fatores desconhecidos fazem da detecção de face um problema muito interessante e desafiante. Uma definição para detecção de face é dada: Dada uma imagem arbitrária ou em seqüência, da qual pode vir de uma imagem digitalizada ou uma fotografia scaneada, o objetivo da detecção de face é determinar se há ou não qualquer face humana na imagem, e se presente, retornar sua localização e extensão espacial.

\subsection{Abordagem Autoface}

Um método de aprendizagem visual probabilístico, baseado na estimação da densidade em um espaço altamente dimensionado usando decomposição de autoespaço, foi desenvolvido por Mogaddam e Pentland [12], [21]. Na análise de componente principal, os maiores autovalores e autovetores são identificados e selecionados como 
componentes principais para formar um subespaço. Estes componentes principais preservam as principais correlações lineares nos dados e discartam as sem importância. Em contraste, tem-se a forma de uma decomposição ortogonal do espaço vetor dentro de dois subespaços mutuamente exclusivos e complementares: o subespaço principal (ou espaço de características) e seus complementos ortogonais. Então, a densidade objetivo é decomposta em dois componentes: a densidade em um subespaço principal (transposto por componentes principais) e seus complementos ortogonais (os quais são descartados na análise de componente principal padrão). A multivariável Gaussian e uma mistura de variáveis Gaussians são usadas para aprender as características estatísticas de características locais de uma face. Estas densidades probabilidades são então usadas para detecção de objeto baseadas em uma estimação de probabilidade máxima. O método proposto tem sido aplicado para localização de face, codificação e reconhecimento. Comparada com a clássica abordagem autoface, o método proposto mostra melhor desempenho no reconhecimento de face. Em termos de detecção de face, suas técnicas tem sido somente demonstradas na localização (isto é, assumindo que uma imagem de entrada possui somente uma face).

\subsection{Abordagem Probabilística}

Em [52] apud [21] Schneiderman e Kanade descrevem um modelo probabilístico para reconhecimento de objeto baseado primeiramente na aparência do local, o qual difere significativamente da aparência baseada no método que enfatiza a aparência global. Esta abordagem é comparada a métodos nos quais modela o todo, extensão global do objeto, e neste caso a face humana, junto. A razão deles enfatizarem a aparência local é que alguns padrões locais no objeto são mais únicos do que outros. Para faces humanas, os padrões de intensidade ao redor dos olhos de uma face humana são mais exclusivos do que o padrão encontrado nas bochechas. Para representar a aparência exclusiva do local, aparências estatísticas e local necessitam ser modeladas. A razão delas usarem uma forma funcional de função de probabilidade posterior é capturar a junção estatística da aparência local e posição no objeto bem como as estatísticas da aparência local. Este modelo probabilístico de relacionamento entre aparência local e spacial mostra desempenho comparável com a detecção de face baseadas em redes neurais.

Em [53] apud [21] uma alta ordem estatística baseada em algoritmos de aglomeração e um modelo Markov escondido, esquema (HMM) são propostos para detecção de face. No primeiro método, a distribuição desconhecida da face e face com cópia são modeladas usando alta ordem estatística. A conjectura é que a distribuição de diferentes padrões face deve ser governada por funções Gaussian multidimensionais. Um perceptron multicamada é usado para classificação, em [45] apud [21]. O segundo método usa uma HMM para aprender entre face e não face e transições de face e não face. A sequência de observação é gerada no domínio de transformação pela comparação de cada subimagem máscara com uma base de conhecimento consistindo de 6 faces e 6 faces como centróides, similar a métrica de distância usada em [45] apud [21]

\section{Exemplo de Ferramenta de De- tecção de Face com Técnicas Es- tatísticas}

A seguir é apresentado uma ferramenta desenvolvida por [19] usando técnicas estatísticas (Autofaces e Pirâmide de Gaussian) para a detecção de face.

\subsection{Objetivo}

O objetivo da ferramenta é detectar faces de diferentes tamanhos em imagens em escala de cinza. O programa desenha um contorno quadrado ao redor da posição na imagem de entrada onde a probabilidade de se encontrar uma face é máxima.

\subsection{Considerações}

- Há exatamente uma face na imagem de entrada.

- As faces aparecem aproximadamente em visões frontais.

- As faces não são inclinadas ou rotacionada na imagem.

\subsection{Algoritmo}

$\mathrm{O}$ algoritmo usado para a detecção de face foi baseado em uma sugestão de Moghaddam e Pentland [12].

\subsubsection{Determinações}

- Foram determinadas 42 autofaces e autovalores e a face média, i.e., $N=42$.

- Foram determinados códigos MATLAB para geração de pirâmides.

\subsubsection{Passos de Pré-Processamento}

- A face média e cada uma das autofaces são cortadas até que somente as partes não zero sejam retidas. Isto poupa a computação sem afetar o resultado pela rejeição dos zeros que cercam as imagens.

- A imagem de entrada é escalada por $(3 / 4)$ na direção $x$ para fazer a relação largura e altura da entrada iguais as das imagens usadas no conjunto de treinamento, para geração das autofaces. 


\subsubsection{Parâmetros}

Os valores dos parâmetros foram mantidos para todas as imagens mostradas.

- $M$, o número de autofaces usadas para a detecção de face, $M=20$.

- Rho, o multiplicador que determina o peso da distância dos espaços de características (DFFS) relativa a distância do espaço de fatores (DIFS). Para esta simulação mostra-se: $R h o=(1 /(N-M)) *$ sum(autovalores $(M+1: N))$.

- O número de níveis capaz de construir a imagem de entrada.

\subsubsection{Algoritmo}

- Uma quarta-oitava pirâmide de Laplace é construída pela junção de todas as 4 pirâmides oitavas completas gerada pela imagem de entrada e escaladas abaixo da versão delas.

- A cada escala desta pirâmide, uma janela de entrada de mesmo tamanho da face média aparada é correlacionada com a face média aparada. Antes da correlação, se a entrada inteira para esta escala ou a janela de entrada são normalizadas assim que elas obtém a mesma iluminação e variância média como a face média aparada.

- A cada escala da pirâmide e cada janela de entrada, a distância Mahalanobis é computada adicionando a distância no espaço de características (DIFS) e a distância do espaço de características (DFFS). Em alguns casos, melhores desempenhos são obtidos usando somente DIFS e ignorando DFFS.

- A janela de entrada é então deslocada ao redor de todas as partes da imagem de entrada na escala atual da pirâmide e os cálculos acima são repetidos.

- A posição da mínima distância de Mahalanobis que cruza todas as escalas e posições na janela de entrada é encontrada. Esta é a posição e a escala onde a probabilidade de se encontrar uma face na imagem é máxima.

\subsection{Imagens de Saída}

As seguintes imagens foram obtidas tanto pelo uso da distância DFFS como da DIFS: Fig.10, Fig.11, Fig.12.

Imagem obtida usando somente a distância DIFS e ignorando DFFS, Fig. 13.

Imagens onde o programa falha: Fig.15 e Fig.14.

\subsection{Desempenho}

O programa tem sucesso no encontro de 8 das 10 faces segundo demonstrado em [19]. Interessantemente, em uma das imagens onde ela falha, ele parece preferir uma face de lado, parcialmente ocluída ao fundo com relação à face

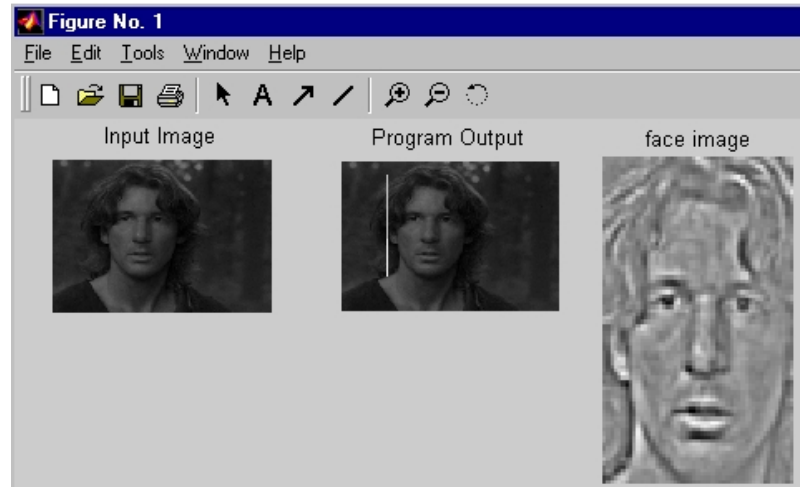

Figura 10: Exemplo 1 de imagem obtida pelo uso das distâncias DFFS e DIFS

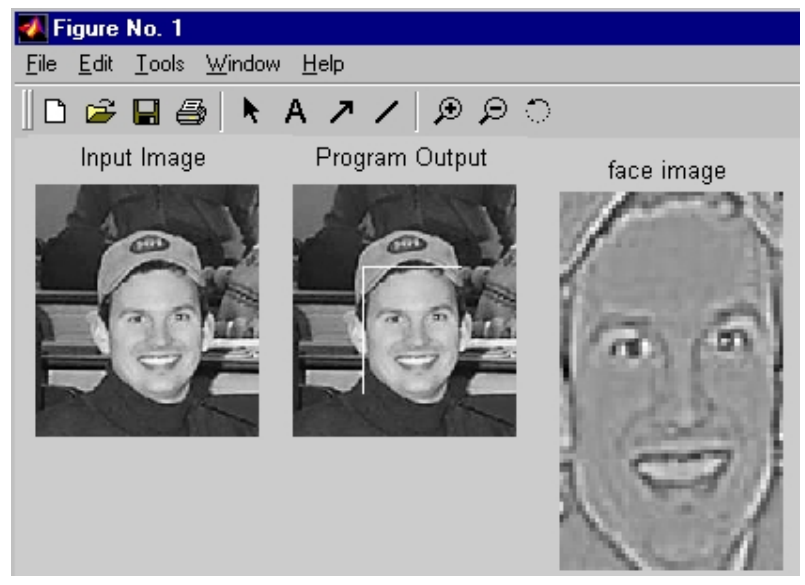

Figura 11: Exemplo de imagem obtida pelo uso das distâncias DFFS e DIFS

que está de frente, veja Fig.14. Este problema pode ser resolvido usando mais níveis na pirâmide Laplaciana da entrada.

\subsection{Problemas e Críticas Apresentadas}

- A abordagem autoface para reconhecimento de face essencialmente amarra a imagem de entrada ao conjunto de treinamento dentro de um vetor e computa os autovalores e autovetores deste conjunto de vetores. Isto não faz qualquer utilidade no uso de propriedades geométricas das mesmas faces, tais como a localização dos olhos, com relação ao nariz e a outras características faciais. Isto faz a abordagem ser geral em que se possa classificar e reconhecer qualquer tipo de objeto baseada nas imagens de treinamento. Ao mesmo tempo, isto lança muitas informações sobre características faciais. Isto também faz o método ser altamente improvável de se parecer com maneira como os humanos reconhecem faces. O sucesso do algoritmo depende largamente da generalização do conjunto de treinamento usado para gerar as autofaces.

- Este algoritmo não pode detectar faces que são muito menores do que a face média. Este pro- 


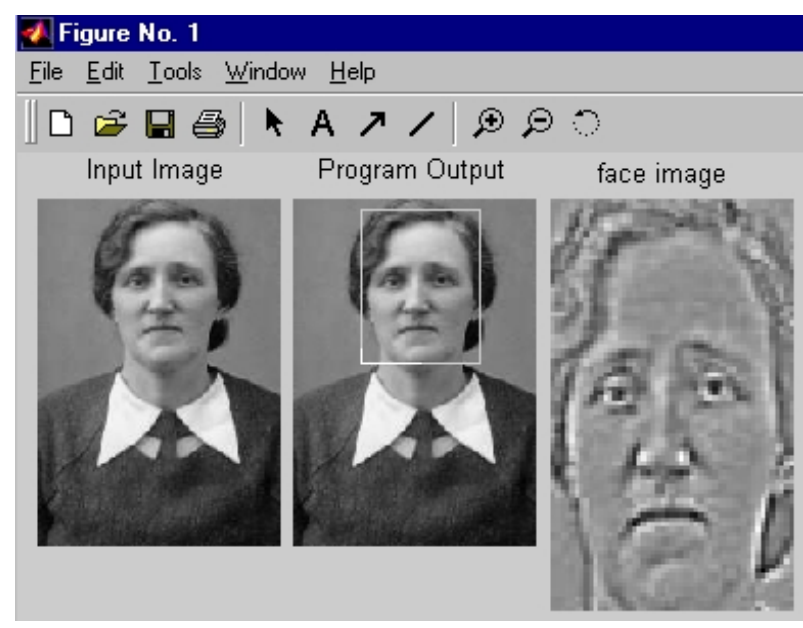

Figura 12: Exemplo de imagem obtida pelo uso das distâncias DFFS e DIFS

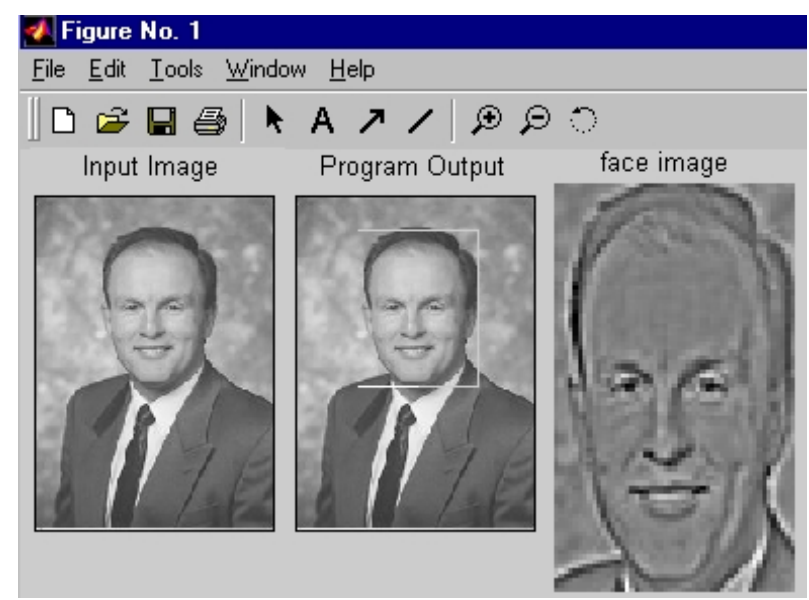

Figura 13: Exemplo de imagem obtida pelo uso somente da distância DIFS e ignorando DFFS

blema pode ser resolvido pela construção de pirâmides para as autofaces, a face média e a entrada. Entretanto, isto aumenta enormemente o número de cálculos. Enquanto se faz isto, deve-se ter o cuidado com a escala de uma autoface por um fator de $(1 / m)$ acompanhada por uma escala de autovalores correspondentes por um fator de $(1 / m)^{2}$.

- O desempenho é altamente dependente da largura $\mathrm{x}$ altura nas imagens de entrada.

- Na maioria dos casos, o uso de DFFS melhora o desempenho, mas em alguns, ele atrasa o desempenho. A escolha de usar ou não usar a distância DFFS se dá pela experiência.

\subsection{Implementação}

Esta ferramenta de detecção de face foi programada em MATLAB 5.2 usando a caixa de ferramentas de processamento de imagem. O código desta aplicação foi dividido nos seguintes arquivos:

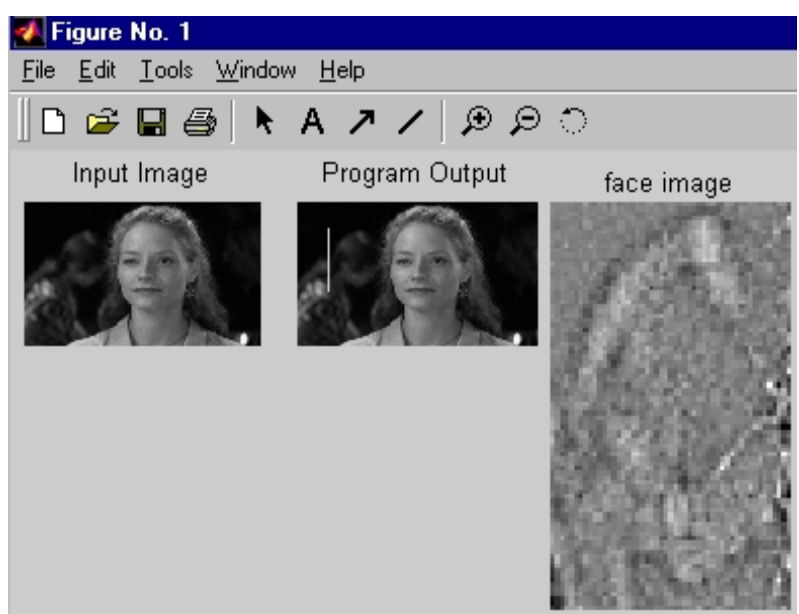

Figura 14: Exemplo de imagem onde o programa falha na deteção

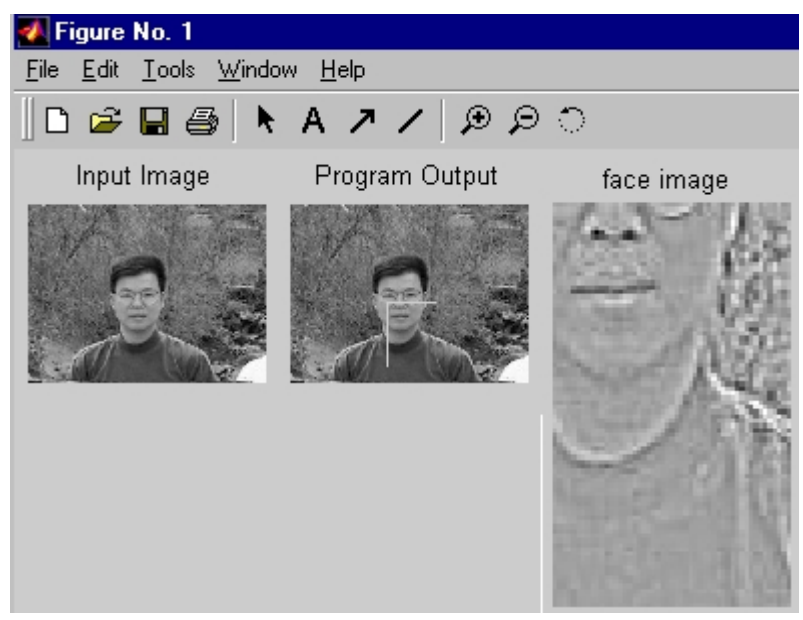

Figura 15: Exemplo de imagem onde o programa falha na deteção

- face.m: Programa principal. Este arquivo detecta a face na imagem de entrada.

- makeImPyr.m: Função que constrói uma pirâmide Laplaciana quarta-oitava pela junção de quatro pirâmides oitavas completas, geradas das versões de escalas da entrada.

- plot_eigen.m: função que esboça a face média aparada e autofaces.

- suptitle.m: Código obtido da página da MATHWORKS para colocar um título sobre todas subimagens em uma figura (escrito por Drea Thomas,drea@mathworks.com)

- matlabPyrTools.tar.gz: Código fonte com ferramentas de pirâmide MATLAB (do departamento CIS da Universidade da Pensilvânia )

Outros arquivos necessários:

- average_face.mat (131Kb)

- eigenfaces.mat (5.5 Mb) 
- eigenvalues.mat

- showme.m

\section{Conclusão}

Este trabalho teve como objetivo apresentar um estudo sobre reconhecimento de padrões estatístico e mostrar vários exemplos de abordagens estatísticas empregadas no reconhecimento de faces humanas. Dentre as várias abordagens vistas, temos que o método de correlação atua com alta precisão, se iluminação artificial e normalização do tamanho são aplicadas, sob variações na expressão facial e posições. Entretanto, este método é computacionalmente muito complexo. A mais eficiente abordagem para o reconhecimento de face é o método autoface. Embora o desempenho de reconhecimento é menor do que o método de correlação, a redução significativa na complexidade do método autoface faz este método ser mais atrativo. A taxa de reconhecimento aumenta com o número de componentes principais usados (autofaces) e quanto mais componentes principais são usados, o desempenho aproxima-se do da correlação. Vimos que por meio da abordagem paramétrica, onde os parâmetros são conhecidos e

ou estimados, extende-se a capacidade do método Autoface para reconhecimento de objetos em imagens 3D, fazendo com que um espaço paramétrico descreva a identificação de um objeto visualização e iluminação. A partir da decomposição deste espaço desenvolveu-se uma abordagem em autoespaço chamada "view-based"que se realiza sob condição gerais de visão, para o reconhecimento de face.

No reconhecimento de faces usando autoCaracterísticas são utilizadas características faciais gerando uma representação modular da face e sua potencial vantagem é a habilidade de superar as desvantagens do método autoface padrão, que pode ser facilmente enganado por grosseiras variações na imagem de entrada (chapéu, barbas, etc). O método de discriminante linear de Fisher é proposto para reduzir a dimensionalidade do espaço de características, como exemplos teve-se os trabalhos de [19] e [20] apud [13] nos quais tratam respectivamente, Autofaces x Fisherfaces no reconhecimento usando classes específicas de projeções lineares e reconhecimento de faces usando discriminantes autovetores.

Já o método baseado em HMM o qual é bem sucedido no reconhecimento de voz, mostrou que é significantemente melhor para o reconhecimento de face do que o método Autoface. Isto é devido ao fato de que o método baseado em HMM oferece uma solução para detecção de características faciais bem como reconhecimento de face. Entretanto a 1D HMM contínuas são computacionalmente mais complexas do que o método Autoface. A solução é reduzir o tempo de execução deste método com o uso de HMM discreta.

Foi apresentado também um método que reúne misturas de subespaços linear local, que tem melhor e mais robusto desempenho do que o classificador "vizinho mais próximo"operando em um subespaço de análise componente principal ou expansão Karhunen-Loëve.

Foi apresentado também um breve estudo sobre métodos de detecção de face com abordagens estatísticas, e para que um sistema de detecção de face seja robusto, projetistas devem-se preocupar com os seguintes problemas: utilização de mistura de diferentes classificadores, efeitos das condições de iluminação, detecção da face em diferentes posições, experimentos empíricos para comparações e uma base de dados para possibilitar um "bechmark". Recentemente muitas abordagens estatísticas usam uma mistura Gaussian ou uma mistura de subespaços para reconhecimento de faces humanas. O problema é que face humana é algo que não pode ser propriamente representado por um padrão simples aglomerado. Além do mais, a maioria dos sistemas de detecção usam faces com expressões neutras e poucas características faciais.

Para se construir um sistema de detecção que possa identificar faces, é natural esperar que diferentes aglomerados sejam melhor representados por diferentes subespaços. Deteção da face é um problema muito desafiante e interessante, e portanto é o primeiro passo prático e importante para se construir um completo sistema de reconhecimento de face automático. E como há um enorme e crescente interesse nas interações humano-computador, é importante investigar métodos que possam ter desempenhos cada vez mais rápidos e robustos.

\section{Referências}

[1] BARreto, J. M. Inteligência Artificial no Limiar do Século XXI, 3 ed. RôRôRô Edições, Florianópolis, SC, 2001.

[2] Belhumeur, P. N.; ao P. Hespanha, J. \& KriEGMAN, D. J. Eigenfaces vs. fisherfaces: Recognition using class specific linear projection. IEEE Transactions on Pattern Analysis and Machine Intelligence 19, 7 (July 1997), 711-720.

[3] DE Oliveira MARIN, L. Investigaç oes sobre redes neurais artificiais para o reconhecimento de faces humanas na forma 3D. Dissertação de Mestrado, Universidade Federal de Santa Catarina, Ciência da Computação, Florianópolis, agosto 2003.

[4] Dieudonné, J. Foundations of modern analysis. Academic Press, New York, 1969.

[5] Frey, B. J.; Colmenarez, A. \& Huang, T. S. Mixtures of local linear subspaces for face recognition. Computer Vision and Pattern Recognition 98 (June 1998).

[6] Gevers, M. \& Barreto, J. M. Un modèle formel du problème de l'inférence de cladogrammes. Comptes Rendus Academie des Sciences de Paris, tomo 309, série III (1989), 557-561. 
[7] Hallinan, P. L.; Gordon, G. G.; Yuille, A. L.; Giblin, P. \& MuMford, D. Two- and Three-Dimensional Patterns of the Face. A K Peters, Ltd, 1999.

[8] JAIn, A. K.; DuIn, R. P. W. \& MAO, J. Statistical pattern recognition: A review. IEEE Transactions on Pattern Analysis and Machine Intelligence 22, 1 (January 2000), 4-37.

[9] KASRIEL, R. H. Undergraduate topology. W. B. Saunders, Philadelphia, 1971.

[10] LI, S. Z. Face recognition based on nearest linear combinations. Scholl of EEE, Nanyang Technological University, Singapore.

[11] Marin, L. O.; Barreto, J. M.; ZimMERMAnN, A. C. \& EnCINAS, L. S. 3D Human face recognition as a linearly separated problem. In International Conference on Artificial Intelligence and Applications, Innsbruck, Fev. 2004, IASTED, Acta Press, Anahaim, p. 385-289.

[12] Moghaddam, B. \& Pentland, A. Face recognition using view-based an modular eigenspaces. Automatic Systems for the Identification and Inspection of Humans, SPIE 2277, 301 (July 1994).

[13] Nefian, A. V. Statistical Approaches To Face Recognition. Degree of doctor of philosophy in electrical engineering, Georgia Institute of Technology - Scholl of Electrical Engineering, December 1996.

[14] PAVEL, M. Reconnaissance des structures. Hermann, Paris, 1969.

[15] SPIES, H. Face recognition - a novel technique. Masther thesis summary.

[16] ThORndike, E. L. Animal Intelligence. www.dominiopublico.gov.br, 1911. (acesso em 13/07/2006).

[17] Tou, J. T. \& Gonzales, R. C. Pattern recognition principles. Addison-Wesley, Massachusets, 1974.

[18] Turk, M. A. \& Pentland, A. P. Face recognition using eigenfaces. In Proc. of the IEEE Computer Society Conferece. IEEE Computer Society Press (1991).

[19] Viswanatha, L. Eigenfaces and gaussian pyramids. URL:http://cns.bu.edu/ lavanya/Grafhics/cs585/p2/p2.html, October 1998.

[20] Watanabe, S. Pattern Recognition: Human and Mechanical. Wiley, New York, 1985.

[21] Yang, M. H.; Ahuja, N. \& Driegman, D. A survey on face detection methods.
[22] Zimmermann, A. C.; Encinas, L. S.; Marin, L. O. \& BArreto, J. M. Comparing CBR and NN performancein a 3-Dface recognition. In International Conference on Artificial Intelligence and Applications, Innsbruck, Fev. 2004, IASTED, Acta Press, Anahaim, p. 661-665.

[23] Zimmermann, A. C.; Gonçalves Jr., A. A. \& BARRETo, J. M. A 3D object extraction and recognition method. In International Conference on Control, Automation, Robotics and Vision, Singapura, dez. 2000, .

[24] Zimmermann, A. C.; Gonçalves Jr., A. A. \& Barreto, J. M. Projeto Sorface, http://www.labmetro.ufsc.br/sorface/. Relatório técnico., LCCC-UFSC, Florianópolis, dez. 2001.

[25] Zimmermann, A. C.; Marin, L. O. \& BarRETO, J. M. Training set optiization in 3D human face recognition by RBF neural networks. In $\mathrm{Neu}$ ral Netwoks and Computational Inelligence, Grindelwald, March 2004, p. 222-225. 